\title{
Pre-eclampsia and the later development of type 2 diabetes in mothers and their children: an intergenerational study from the Walker cohort
}

\author{
G. Libby • D. J. Murphy • N. F. McEwan • S. A. Greene • \\ J. S. Forsyth • P. W. Chien • A. D. Morris • \\ for the DARTS/MEMO Collaboration
}

Received: 30 August 2006 / Accepted: 1 November 2006 / Published online: 23 December 2006

(C) Springer-Verlag 2006

\begin{abstract}
Aims/hypothesis Studies have shown a relationship between pre-eclampsia and later coronary artery disease. This study investigated whether there is a relationship between pre-eclampsia and the development of type 2 diabetes in mothers and their babies and how this is affected by infant birthweight.

Subjects and methods This was an intergenerational cohort study. The study population comprised 7,187 mothers who gave birth and 8,648 babies who were born in Dundee, Scotland between 1952 and 1958. Their later diabetic status was defined from 1980 to 2003 by linkage to populationbased datasets.
\end{abstract}

G. Libby $(\bowtie) \cdot$ A. D. Morris

Division of Community Health Sciences,

University of Dundee,

The Mackenzie Building, Kirsty Semple Way,

Dundee DD2 4BF, UK

e-mail: g.libby@chs.dundee.ac.uk

D. J. Murphy $\cdot$ S. A. Greene $\cdot$ J. S. Forsyth $\cdot$ P. W. Chien

Division of Maternal and Child Health Sciences,

Ninewells Hospital and Medical School, University of Dundee,

Dundee, UK

N. F. McEwan • A. D. Morris

Division of Medicine and Therapeutics,

Ninewells Hospital and Medical School, University of Dundee,

Dundee, UK

D. J. Murphy

Department of Obstetrics and Gynaecology, Trinity College,

University of Dublin,

Dublin, Ireland
Results There were 810 (11.3\%) mothers with preeclampsia and 745 (10.4\%) who subsequently developed type 2 diabetes. Logistic regression showed an increased risk of developing type 2 diabetes for mothers with preeclampsia, unadjusted odds ratio (OR) 1.37 (95\% CI 1.10$1.71), p=0.005$. This relationship persisted after adjustment for infant birthweight, OR 1.40 (95\% CI 1.12-1.75), $p=0.003$. Of the babies born between 1952 and 1958, 221 (2.6\%) had developed type 2 diabetes, 137 of them male ( $2.9 \%$ of male subjects in study population) and 84 female ( $2.2 \%$ of female subjects). The relationship between preeclampsia in the mother and the risk of type 2 diabetes in the offspring did not reach statistical significance, OR 1.38 (95\% CI $0.90-2.10)$. Babies with birthweight in the lowest quintile (adjusted for sex, gestation and birth order) had an increased risk of developing type 2 diabetes, OR for lowest quintile vs highest quintile 1.84 (95\% CI 1.24 2.72), $p=0.002$.

Conclusions/interpretation Pre-eclampsia is associated with increased risk of developing type 2 diabetes in the mother, but birthweight is a more important determinant of future risk for the offspring.

Keywords Birthweight - DARTS/MEMO collaboration . Diabetes $\cdot$ Pre-eclampsia $\cdot$ Walker cohort

$\begin{array}{ll}\text { Abbreviations } \\ \text { CHNo } & \text { community health index number } \\ \text { DARTS } & \text { Diabetes Audit and Research Tayside } \\ \text { ICD } & \text { International Classification of Diseases } \\ \text { IQR } & \text { interquartile range } \\ \text { IUGR } & \text { intrauterine growth restriction } \\ \text { MEMO } & \text { Medicines Monitoring Unit } \\ \text { OR } & \text { odds ratio }\end{array}$




\section{Introduction}

Pre-eclampsia remains one of the commonest causes of maternal and fetal morbidity and mortality. However, the long-term consequences of a diagnosis of pre-eclampsia for mothers and their babies are uncertain. Women with gestational hypertension and pre-eclampsia appear to develop later chronic hypertension [1-3], especially when the hypertension in pregnancy is before 30 weeks of gestation [4]. In terms of adverse outcome, several recent studies have reported that a history of pre-eclampsia may predict an increased risk of coronary heart disease, but the underlying mechanism remains uncertain. One plausible explanation is that pre-eclampsia is a marker of an adverse metabolic phenotype associated with insulin resistance and type 2 diabetes. Recent observational studies that suggest women with a history of gestational hypertension and preeclampsia have higher waist circumference, WHR and $\mathrm{BMI}$, as well as increased fasting insulin, lipid and coagulation factor concentrations post-partum [5-7], support this hypothesis. Although several studies have confirmed an insulin-resistant metabolic profile of pre-eclamptic mothers, no studies have been sufficiently large, or have had sufficient follow-up, to investigate the relationship between preeclampsia and the development of type 2 diabetes in later life. The aim of this study, therefore, was to use a large birth cohort with linked population-based databases to test the hypothesis that there is an association between pre-eclampsia and the development of type 2 diabetes in both mothers and their babies in later life and to explore whether this was reflected in infant birthweight.

\section{Subjects and methods}

Study design

We performed two parallel cohort studies to investigate the association between pre-eclampsia (including eclampsia) and: (1) the development of type 2 diabetes in the mothers in later life; and (2) the development of type 2 diabetes in their offspring in later life.

Detailed pregnancy and birth information was obtained from the Walker database [8], which contains meticulously recorded details, according to a pre-defined dataset on purpose-written cards, of the majority of babies and their mothers born in Dundee (the major urban centre in Tayside) from 1952 to 1966 . We studied the babies born between 1952 and 1958, as this period corresponded with a well defined set of variables that had been recorded for all babies. In addition, for the babies' study, individuals born during this early part of the cohort were most likely to be of an age, at the time of the study, when development of early- onset type 2 diabetes would be apparent. The demographic information on the Walker database was used to allocate a community health index number ( $\mathrm{CHNo}$ ), a unique patient identifier that is used extensively in Tayside, Scotland, to identify episodes of healthcare activity. For both cohort studies data from the Walker database were linked to data from the Diabetes Audit and Research Tayside (DARTS) and Medicines Monitoring Unit (MEMO) collaboration, which includes a series of databases of health outcomes that are record-linked by the CHNo.

Mothers and type 2 diabetes study

The identification of the mothers' cohort is shown in Fig. 1. Pre-eclampsia was considered to be a characteristic of the mother, rather than of an individual pregnancy, and therefore exposure to eclampsia or pre-eclampsia was defined as any pregnancy between 1952 and 1966 with this diagnosis. Pre-eclampsia was defined as a rise in diastolic blood pressure after the 26th week of pregnancy to $\geq 90 \mathrm{mmHg}$ on two or more occasions separated by at least 1 day, together with confirmed albuminuria.

The outcome of type 2 diabetes was defined according to WHO criteria [9] and was confirmed by manual validation of case records of all diabetic patients in Tayside. By linking to the DARTS database [10], the CHNo was used to identify all cases of diagnosed type 2 diabetes in mothers who were alive and resident in Tayside between 1 January

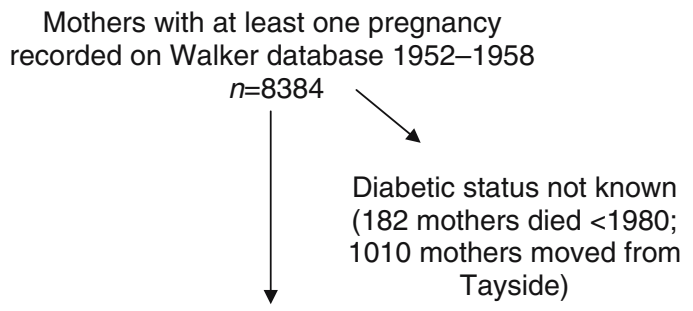

Mothers resident in Tayside 2003

or died in Tayside 1993-2003
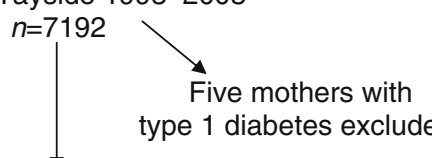

First recorded pregnancy 1952-1958 = index pregnancy $n=7187$

in any pregnancy 1952-1966

$n=810(11.3 \%)$

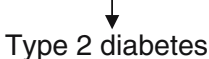

$n=107(13.2 \%)$

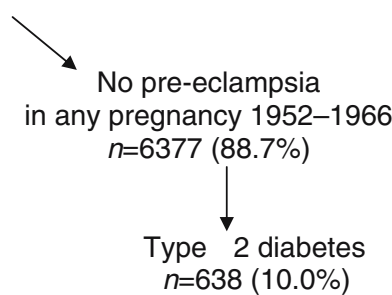

Fig. 1 Cohort identified for mothers' study 
1993 and 31 March 2003 or had died in Tayside during this period. The DARTS database contains details of all subjects in Tayside diagnosed with diabetes since 1993. Mothers who died between 1980 and 1993 were identified as diabetic if they had had more than one prescription for insulin or oral hypoglycaemic medication (British National Formulary Chapter 6.1.1 and 6.1.2) and/or had had at least one hospital admission for type 2 diabetes (International Classification of Diseases [ICD]9 Code 250 or ICD10 Codes E10 or E11).

Babies and type 2 diabetes study

Not all babies had a mother for whom a CHNo could be identified and so it was not possible to identify all sibling pregnancies. Babies were classified as being exposed to eclampsia or pre-eclampsia only if their mother had experienced the condition during the pregnancy from which they were born. The babies' cohort therefore potentially contained siblings, but each baby was treated as an independent entity, as the baby rather than the mother was the subject of interest. Type 2 diabetes was then identified in both the exposed and unexposed groups by linking to the DARTS diabetes database. The identification of the babies' cohort is shown in Fig. 2.

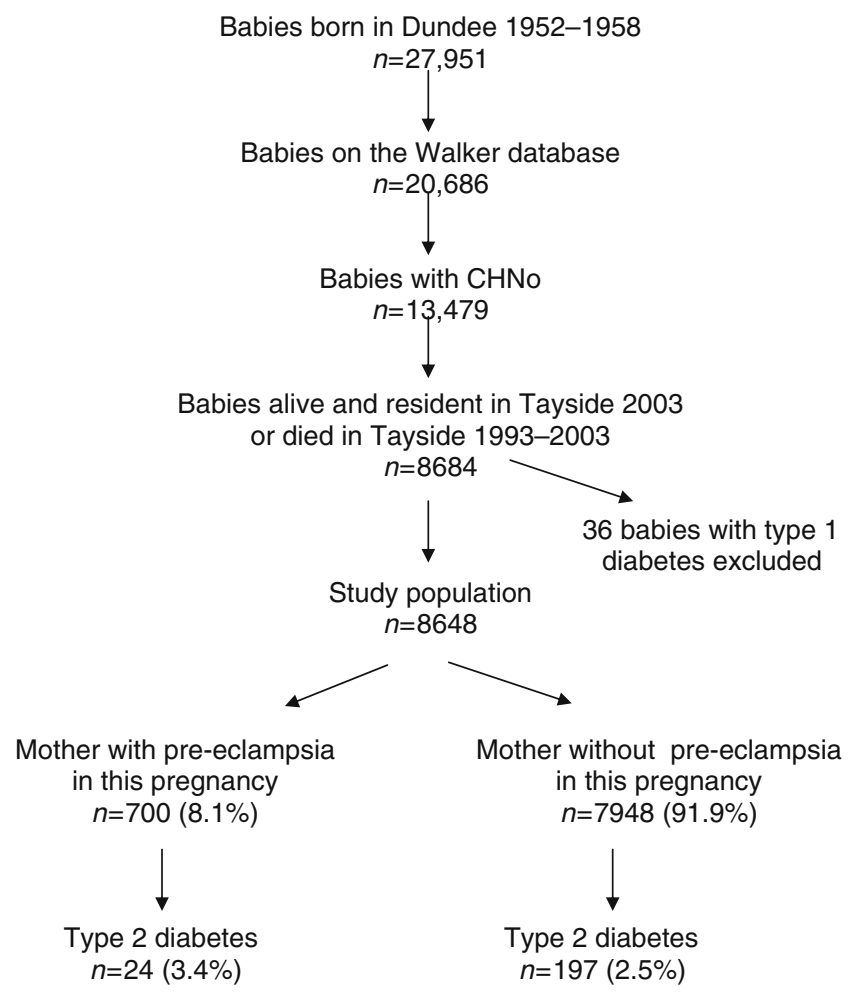

Fig. 2 Cohort identified for babies' study

\section{Statistical methods}

In both studies we compared the baseline clinical characteristics of the subjects (i.e. mothers and babies) with and without a CHNo to evaluate the representative nature of the subjects studied.

A power calculation showed that 7,200 subjects were required to detect an odds ratio (OR) of 1.4 with $80 \%$ power at the $5 \%$ level.

The relationships between type 2 diabetes and: (1) offspring birthweight in the mothers' study; and (2) birthweight in the babies' study were both curvilinear and therefore birthweight was categorised into quintiles. These were calculated using the entire cohort of more than 47,000 Walker babies adjusting for gestational age, sex and parity.

Mothers' study A logistic regression analysis was performed to compare the risk of type 2 diabetes in mothers with and without pre-eclampsia. The model was performed unadjusted and then adjusted for quintiles of birthweight of the baby in the index pregnancy, as studies have shown that birthweight of offspring is inversely related to the mother's insulin resistance in late adulthood.

Adjustment was also made for increasing age and deprivation, which are potential risk factors for the development of type 2 diabetes. Deprivation level was identified using the Carstairs score [11], which is derived from the postcode. It ranges from category 1 (least deprived) to 7 (most deprived). There were few subjects in category 7 so this was combined with category 6 .

Babies' study Babies with type 2 diabetes were all identified from the DARTS database and again logistic regression analysis was used to examine the future risk of developing type 2 diabetes as a result of exposure to eclampsia or pre-eclampsia during fetal development. Low birthweight has also been linked to the development of type 2 diabetes in individuals and so the analysis was adjusted for the same potential confounding variables as in the mothers' study.

In addition, babies who were small for gestational age, i.e. in the lowest centile of birthweight adjusted for sex, gestation and parity, were identified.

\section{Ethical approval}

We obtained ethical approval from the Multi-Centre Research and Ethics Committee for Scotland, and the three local NHS Caldicott Guardians also approved the study. All data in MEMO are anonymised prior to analysis to maintain confidentiality and conformance with the data protection act. 


\section{Results}

Mothers and type 2 diabetes study

The study population consisted of 7,187 mothers. A comparison of mothers with and without a CHNo showed little difference between the groups. For the index pregnancy, mothers with a CHNo were less likely to have had complications during the pregnancy, but were more likely to have been breastfeeding at the time of discharge ( 83.7 vs $75 \%$ ) and were slightly older (median 26 vs 25 years).

Of the 7,187 mothers in the study population, 5,038 $(70.1 \%)$ were still alive and resident, 2,131 (29.6\%) had died and the status of the remaining 18 was not known. There was no difference in the proportion of mothers who had died by pre-eclamptic status $(30.2 \%$ with pre-eclampsia vs $29.7 \%$ without). Those alive had a median age of 72 (interquartile range [IQR] 69-76) years compared with 69 (IQR 62-74) years for those who had died.

There were $810(11.3 \%)$ mothers with pre-eclampsia, and differences between the mothers with and without preeclampsia are shown in Table 1. As would be expected, preeclampsia was associated with primiparity and lower infant birthweight, with a greater number of infants being small for gestational age. Altogether 745 (10.4\%) mothers subsequently developed type 2 diabetes, of these 684 $(92 \%)$ were identified from the validated DARTS dataset. The median age at diagnosis was 66 (IQR 60-71) years. There was no difference in age at diagnosis of diabetes between mothers who had been exposed to pre-eclampsia and those who had not.

The logistic regression analysis showed an increased risk of developing type 2 diabetes for mothers with preeclampsia in at least one pregnancy, unadjusted OR 1.37 (95\% CI 1.10-1.71), $p=0.005$. Increasing age was associated with developing type 2 diabetes and also having a baby with a higher birthweight. When all the variables were put into the analysis, the relationship between pre-eclampsia and type 2 diabetes was virtually unchanged $(\mathrm{OR}=1.40$ [95\% CI 1.12-1.75], $p=0.003$ ) (Table 2).

It is possible that some mothers classified as not exposed to pre-eclampsia had had the condition in an earlier pregnancy not recorded on the Walker database, because it was prior to 1952 . The analysis was therefore repeated with the study population modified to consist only of those mothers who had at least their first pregnancy recorded on the Walker database. The OR of 1.34 for this analysis $(n=3475)$ was little different to that from the original study $(n=7187)$.

\section{Babies and type 2 diabetes study}

There were 27,951 births in Dundee between 1952 and 1958 , of which $20,686(73.9 \%)$ were on the Walker database; we were able to allocate a CHNo to 13,479 (65.2\% of all Walker births). There was no difference between the babies with and without a CHNo in terms of mother's age and pre-eclamptic status, sex and gestation. The babies with a CHNo were more likely to have been

Table 1 Characteristics of mothers with and without pre-eclampsia

\begin{tabular}{|c|c|c|c|}
\hline & $\begin{array}{l}\text { Mothers with } \\
\text { pre-eclampsia }(n=810)\end{array}$ & $\begin{array}{l}\text { Mothers without } \\
\text { pre-eclampsia }(n=6,377)\end{array}$ & $\begin{array}{l}\text { Odds ratio }(95 \% \mathrm{CI}) \text { or } \\
p \text { value for Wilcoxon tes }\end{array}$ \\
\hline \multicolumn{4}{|l|}{ Birth order of index pregnancy } \\
\hline 1 st $n(\%)$ & $503(62.1)$ & $2,972(46.6)$ & $1.88(1.62-2.19)$ \\
\hline 2nd $n(\%)$ & $156(19.3)$ & $1,571(24.6)$ & $0.73(0.61-0.88)$ \\
\hline $3 \mathrm{rd} n(\%)$ & $60(7.4)$ & $877(13.7)$ & $0.50(0.38-0.66)$ \\
\hline 4 th $+n(\%)$ & $91(11.2)$ & $958(15.0)$ & $0.72(0.57-0.89)$ \\
\hline Mother's age at index pregnancy (median years, IQR) & $25(22-30)$ & $26(22-30)$ & $p=0.7$ \\
\hline Male baby $(n[\%])$ & $436(53.8)$ & $3,434(53.8)$ & $0.99(0.86-1.56)$ \\
\hline Birthweight of baby (median kg, IQR) & $3.29(2.89-3.60)$ & $3.32(3.01-3.63)$ & $p=0.0007$ \\
\hline Gestation (median weeks, IQR) & $40(38-41)$ & $40(39-41)$ & $p<0.0001$ \\
\hline Baby small for gestational age $(n[\%])$ & $109(13.5)$ & $564(8.8)$ & $1.61(1.29-2.00)$ \\
\hline \multicolumn{4}{|l|}{ Carstairs score } \\
\hline $1(n[\%])$ & $54(6.7)$ & $389(6.1)$ & $1.09(0.82-1.48)$ \\
\hline $2(n[\%])$ & $82(10.1)$ & $534(8.4)$ & $1.23(0.96-1.57)$ \\
\hline $3(n[\%])$ & $117(14.4)$ & $898(14.1)$ & $1.03(0.84-1.27)$ \\
\hline $4(n[\%])$ & $167(20.6)$ & $1,151(18.1)$ & $1.17(0.98-1.41)$ \\
\hline $5(n[\%])$ & $43(5.3)$ & $359(5.6)$ & $0.94(0.68-1.30)$ \\
\hline $6(n[\%])$ & $291(35.9)$ & $2,538(39.8)$ & $0.85(0.73-0.99)$ \\
\hline $\begin{array}{l}\text { Mother's age at study or death } \\
\text { (median years, IQR) }\end{array}$ & $71(67-75)$ & $71(67-76)$ & $p=0.4$ \\
\hline
\end{tabular}


Table 2 Characteristics of mothers with and without type 2 diabetes and logistic regression for the development of type 2 diabetes in mothers

\begin{tabular}{|c|c|c|c|c|c|c|c|}
\hline & $\begin{array}{l}\text { Type } 2 \text { diabetes } \\
(n=745)(n[\%])\end{array}$ & $\begin{array}{l}\text { Not type } 2 \text { diabetes } \\
(n=6,442)(n[\%])\end{array}$ & Comparison & $\begin{array}{l}\text { Univariate OR } \\
(95 \% \mathrm{CI})\end{array}$ & $\mathrm{p}$ value & $\begin{array}{l}\text { Multivariate OR } \\
(95 \% \mathrm{CI})\end{array}$ & $\mathrm{p}$ value \\
\hline Pre-eclampsia & $107(14.4)$ & $703(10.9)$ & Yes vs No & $1.37(1.10-1.71)$ & 0.005 & $1.40(1.12-1.75)$ & 0.003 \\
\hline \multicolumn{8}{|l|}{$\begin{array}{l}\text { Offspring birthweight, } \\
\text { quintiles }\end{array}$} \\
\hline Q1 (lowest) ${ }^{\mathrm{a}}$ & $124(16.7)$ & $1,252(19.6)$ & Reference & 1.00 & & 1.00 & \\
\hline Q2 & $137(18.5)$ & $1,331(20.8)$ & Q2 vs Q1 & $1.05(0.82-1.35)$ & NS & $1.06(0.82-1.36)$ & NS \\
\hline Q3 & 159 (21.4) & $1,258(19.7)$ & Q3 vs Q1 & $1.29(1.01-1.65)$ & 0.04 & $1.28(0.99-1.64)$ & NS \\
\hline Q4 & $173(23.2)$ & $1,290(20.2)$ & Q4 vs Q1 & $1.37(1.08-1.74)$ & 0.01 & $1.35(1.06-1.72)$ & 0.02 \\
\hline Q5 & $149(20.1)$ & $1,267(19.8)$ & Q5 vs Q1 & $1.20(0.94-1.54)$ & NS & $1.18(0.92-1.51)$ & NS \\
\hline $\begin{array}{l}\text { Mother's age at study } \\
\text { or at death } \\
\text { (median years, IQR) }\end{array}$ & $72(68-76)$ & $71(67-76)$ & (1 year) & $1.03(1.02-1.04)$ & $<0.0001$ & $1.03(1.02-1.04)$ & $<0.0001$ \\
\hline \multicolumn{8}{|l|}{ Carstairs score } \\
\hline 1 (least deprived) & $34(4.9)$ & $409(6.9)$ & Reference & 1.00 & & 1.00 & \\
\hline 2 & $67(9.8)$ & $549(9.2)$ & 2 vs 1 & $1.13(0.82-1.57)$ & NS & $1.13(0.82-1.57)$ & NS \\
\hline 3 & $96(14.1)$ & $919(15.5)$ & 3 vs 1 & $0.97(0.72-1.30)$ & NS & $0.99(0.74-1.33)$ & NS \\
\hline 4 & $127(18.6)$ & $1,191(20.0)$ & 4 vs 1 & $0.99(0.75-1.31)$ & NS & $1.02(0.77-1.35)$ & NS \\
\hline 5 & $46(6.7)$ & $356(5.9)$ & 5 vs 1 & $1.20(0.83-1.74)$ & NS & $1.22(0.84-1.77)$ & NS \\
\hline 6 & $312(45.7)$ & $2,519(42.4)$ & 6 vs 1 & $1.15(0.90-1.46)$ & NS & $1.23(0.96-1.56)$ & NS \\
\hline
\end{tabular}

${ }^{\text {a }}$ Quintiles of offspring birthweight adjusted for sex, gestation and birth order

breastfed ( $84 \%$ vs $81 \%)$ and had a slightly higher mean birthweight $(3,308 \mathrm{~g}$ vs $3,271 \mathrm{~g})$, though this is not thought to be clinically significant.

Of the 13,479 babies with a CHNo, 8,678 were still alive and resident in Tayside between 1993 and 2003 and six had died during this period, making a total of 8,684 . From these 8,684 we excluded 36 babies with type 1 diabetes leaving 8,648 babies who formed the study population. They were compared for the same key variables with the rest of the babies with a CHNo who were presumed to have moved from the Tayside area. There was very little difference between the groups showing that the study population was representative of the population comprising the Walker database. The babies alive and resident had a median age of 46.5 (IQR 44.8-48.4) years. Those who had died were aged between 40 and 45 years. There was no difference in age between male and female subjects.

A total of $221(2.6 \%)$ babies had developed type 2 diabetes, consisting of 137 male babies $(2.9 \%$ of male babies in study population) and 84 female babies (2.2\% of female babies in study population). The median age at diagnosis was 42 (IQR 39.2-45.7) years. Of the babies who developed type 2 diabetes, those with a pre-eclamptic mother were diagnosed at a median age of 40 (IQR 3743) years, compared with 42.6 (IQR 39-46) years for those whose mothers did not have eclampsia or preeclampsia ( $p=0.07$, Wilcoxon).

The logistic regression analysis showed that babies with a pre-eclamptic mother may be at increased risk of developing type 2 diabetes, but the results did not reach statistical significance, $\mathrm{OR}=1.39(95 \%$ CI $0.91-2.15)$. Birthweight in the lowest quintile was associated with increased risk of developing type 2 diabetes as has been shown in previous studies (Table 3 ).

A total of $872(10.1 \%)$ babies were small for gestational age (birthweight $<10$ th percentile for the entire Walker cohort); of these $38(4.4 \%)$ developed type 2 diabetes, compared with $183(2.4 \%)$ who were not small for gestational age, $\mathrm{OR}=1.89$ (95\% CI 1.322.69), $p=0.0005$.

\section{Discussion}

This inter-generational study examined the relationships between pre-eclampsia and the future development of type 2 diabetes in mothers and in their babies. We found that women with a history of pre-eclampsia were at increased risk of type 2 diabetes in later life. In the babies' study we found that birthweight was more important than preeclampsia in the development of type 2 diabetes. This suggests that small babies, including those with isolated intrauterine growth restriction (IUGR) and those with preeclampsia-related IUGR, are likely to be at greatest risk of adult disease.

Pre-eclampsia and development of type 2 diabetes

Our finding of a relationship between pre-eclampsia and the development of type 2 diabetes in later life is consistent with other reports that pre-eclampsia is associated with key 
Table 3 Characteristics of babies with and without the outcome of type 2 diabetes and logistic regression analysis for the development of type 2 diabetes for babies born between 1952 and 1958

\begin{tabular}{|c|c|c|c|c|c|c|c|}
\hline & $\begin{array}{l}\text { Type } 2 \\
\text { diabetes } \\
(n=221) \\
n(\%)\end{array}$ & $\begin{array}{l}\text { Not type } 2 \\
\text { diabetes } \\
(n=8427) \\
n(\%)\end{array}$ & Comparison & $\begin{array}{l}\text { Univariate } \\
\text { OR }(95 \% \mathrm{CI})\end{array}$ & $\mathrm{p}$ value & $\begin{array}{l}\text { Multivariate } \\
\text { OR }(95 \% \mathrm{CI})\end{array}$ & $\mathrm{p}$ value \\
\hline Pre-eclampsia & $24(10.9)$ & $676(8.0)$ & Yes vs No & $1.39(0.91-2.15)$ & NS & $1.38(0.89-2.13)$ & NS \\
\hline \multicolumn{8}{|l|}{ Birthweight quintiles } \\
\hline Q1 (lowest) ${ }^{\mathrm{a}}$ & $73(33.2)$ & $1,669(19.9)$ & Q1 vs Q5 & $1.84(1.24-2.72)$ & 0.002 & $1.77(1.19-2.62)$ & 0.004 \\
\hline Q2 & $39(17.7)$ & $1,774(21.1)$ & Q2 vs Q5 & $0.92(0.59-1.44)$ & NS & $0.89(0.58-1.41)$ & NS \\
\hline Q3 & $46(20.9)$ & $1,626(19.4)$ & Q3 vs Q5 & $1.19(0.77-1.83)$ & NS & $1.16(0.76-1.79)$ & NS \\
\hline Q4 & $23(10.5)$ & $1,676(19.9)$ & Q4 vs Q5 & $0.58(0.34-0.97)$ & 0.04 & $0.57(0.34-0.95)$ & 0.03 \\
\hline Q5 & $39(17.7)$ & $1,650(19.7)$ & Reference & 1.00 & & 1.00 & \\
\hline Age at study (median years, IQR) & $47(46-49)$ & $47(45-49)$ & (1 year) & $1.09(1.02-1.16)$ & 0.01 & $1.09(1.02-1.17)$ & 0.01 \\
\hline \multicolumn{8}{|l|}{ Carstairs score } \\
\hline 1 (least deprived) & $10(5.0)$ & $715(9.0)$ & Reference & 1.00 & & 1.00 & \\
\hline 2 & $15(7.5)$ & $991(12.5)$ & 2 vs 1 & $0.58(0.31-1.07)$ & NS & $0.61(0.33-1.13)$ & NS \\
\hline 3 & $26(13.1)$ & $1,119(14.1)$ & 3 vs 1 & $0.88(0.53-1.49)$ & NS & $0.90(0.53-1.52)$ & NS \\
\hline 4 & $39(19.6)$ & $1,481(18.7)$ & 4 vs 1 & $1.01(0.63-1.62)$ & NS & $1.03(0.61-1.65)$ & NS \\
\hline 5 & $9(4.5)$ & $493(6.2)$ & 5 vs 1 & $0.69(0.33-1.47)$ & NS & $0.71(0.34-1.51)$ & NS \\
\hline 6 & $100(50.3)$ & $3,120(39.4)$ & 6 vs 1 & $1.23(0.82-1.83)$ & NS & $1.24(0.83-1.87)$ & NS \\
\hline
\end{tabular}

${ }^{\text {a }}$ Quintiles of birthweight adjusted for sex, gestation and birth order

components of the metabolic syndrome. Thus, women with a history of pre-eclampsia have higher circulating concentrations of fasting insulin, cholesterol and coagulation factors post-partum than do controls [5, 6]. Compared with women with a history of a healthy pregnancy, they also seem to show endothelial dysfunction independently of maternal obesity, blood pressure and metabolic disturbances associated with insulin resistance or dyslipidaemia [12]. In a cross-sectional study, individuals with a history of preeclampsia displayed insulin resistance with associated compensatory hyperinsulinaemia [13]. This pattern of metabolic and vascular changes in women with a history of pre-eclampsia is consistent with the abnormalities seen in type 2 diabetes at diagnosis. Thus the genotypes and phenotypes underlying vascular disease and type 2 diabetes may also underlie pre-eclampsia. For example, genome wide scans from Finland and China have reported a locus at $9 \mathrm{p} 13$ that is a candidate region for both type 2 diabetes and pre-eclampsia [14]. Although several studies have confirmed an insulin metabolic profile of mothers who have suffered pre-eclampsia [7], this is the first study that is sufficiently large and with sufficient follow-up to investigate the relationship between pre-eclampsia and the development of type 2 diabetes.

Another possible explanation of our results is related to pancreatic beta cell dysfunction. Thus epidemiological data suggest that various perinatal events such as pre-eclampsia, as well as increasing maternal age and increased parity, are associated with an increased risk of beta cell dysfunction and type 1 diabetes $[15,16]$.
There are cogent reasons for looking for an association between pre-eclampsia and type 2 diabetes, as several recent studies have reported that a history of pre-eclampsia may predict an increased risk of CHD. In a study of 374 women with a history of hypertensive complications in pregnancy, the risk of dying from CHD (risk ratio 2.61; 95\% CI 1.11-6.12) was significantly higher among women who had had eclampsia or pre-eclampsia (risk ratio 1.90; 95\% CI 1.02-3.52) than among those with hypertension alone [17]. The Royal College of General Practitioners' oral contraceptive study also reported that a history of preeclampsia increased the risk of cardiovascular conditions in later life (relative risk for future ischaemic heart disease 1.7; 95\% CI 1.3-2.2) [18], and a record linkage study from Scotland has also recently reported an association between pre-eclampsia and later ischaemic heart disease in the mother (risk ratio 2.0; 95\% CI 1.5-2.5) [19]. An important clinical implication of our findings and these other studies linking pre-eclampsia to future ischaemic heart disease is whether this finding can identify women 'at risk' who otherwise might not have been identified, or whether the use of established risk factors such as hypertension and obesity would have identified these 'at risk' women and offered an opportunity for primary prevention.

Birthweight and the development of type 2 diabetes

Numerous reports have suggested an inverse relationship between birthweight and adult cardiovascular disease [20]. More recent reports have addressed a potential relationship 
between birthweight and components of the metabolic syndrome $[21,22]$. Our findings also show a statistically significant relationship between low birthweight and the risk of early-onset type 2 diabetes.

Unlike previous cohort studies, it was possible for us to explore the underlying aetiologies of low birthweight. Babies may be of low birthweight due to prematurity, congenital malformation, pre-eclampsia and IUGR, or they may be 'normal' small babies representing the lower end of a parentally determined spectrum of birthweight. Our detailed pregnancy data allowed us to classify babies as small for gestational age (birthweight $<10$ th centile), and in doing so we found a strong relationship between babies who had been small for gestational age and type 2 diabetes. These high-risk babies are readily identifiable at the time of birth and could be targeted for health promotion programmes. However, the group of babies that were small for gestational age is still a heterogeneous group of small 'normal' and growth-restricted babies. Fetal growth and development work suggests that growth-restricted babies are likely to be more vulnerable to early vascular and metabolic insults [23], but Doppler studies and serial ultrasound scans are required to further classify these groups of babies. Clearly such detailed fetal assessment will not be available for historical cohorts, but it will be important to explore this hypothesis longitudinally with current well-defined populations.

\section{Strengths and weaknesses}

Our study has several strengths including clear definitions of key exposure and outcome variables in the Walker and DARTS datasets. Thus, a diagnosis of eclampsia or preeclampsia was made by consultant obstetrician staff in the 1950 s according to clinical criteria. The prevalence of moderate or severe toxaemia in our study is consistent with the $10 \%$ reported in a recent West of Scotland [24] cohort, but is higher than reported rates in other recent cohorts. The outcome of type 2 diabetes in the DARTS dataset is validated according to $\mathrm{WHO}$ criteria.

One limitation of the study was that for some of those mothers not exposed to eclampsia or pre-eclampsia an earlier first pregnancy was not recorded on the Walker database; they may, therefore, have previously had eclampsia or pre-eclampsia. However, the misclassification of these mothers, on the basis of subsequent pregnancies, as not pre-eclamptic would in fact lead to an underestimation of the strength of the association with type 2 diabetes shown in this study. In addition, over-controlling is a potential problem. If a woman has had a previous pregnancy complication, e.g. IUGR or pre-eclampsia or perinatal death, this may occur along the causal pathway of the association between pre-eclampsia and subsequent type
2 diabetes. It would be unwise therefore to control for this as it may diminish what is possibly a true association. Also, repeating the analysis using only first pregnancies as the index pregnancy showed a similar OR to that of the whole cohort analysis; it would appear therefore that a previous pregnancy had little impact on the reported association.

It is possible that the association between pre-eclampsia and type 2 diabetes in the mother was confounded by gestational diabetes, which was not recorded for this cohort. However, for gestational diabetes to be a true confounder in the relationship between pre-eclampsia and type 2 diabetes, it would need to be associated with pre-eclampsia as well as type 2 diabetes. However, observational studies investigating an association between gestational diabetes and preeclampsia are inconclusive as to whether gestational diabetes confers higher risk of pre-eclampsia [25]. In addition, data from the Walker cohort were recorded before gestational diabetes was routinely identified and this is likely to be the case for all cohorts of mothers who have sufficient follow-up for type 2 diabetes in late adulthood.

We were able to exclude those mothers with type 1 diabetes, but it was not known whether any of the mothers had type 2 diabetes at the time of their pregnancies. The condition, however, would have been extremely rare in the age group of these mothers during the 1950s and 1960s, and not excluding any such mothers from the analysis would therefore seem very unlikely to have biased the results of the study.

Another variable of interest is family history of diabetes. This was not included as a risk factor for developing diabetes as it was not available for the mothers and only for a minority of the infants. In the same way, pre-pregnancy BMI would also have been useful but was not available.

In conclusion, pre-eclampsia is associated with the future development of type 2 diabetes in mothers, but birthweight is a more important marker of risk for the offspring. Pregnancy complications may allow early identification of individuals at increased risk of metabolic disease in later life across two generations of the same family.

Acknowledgements The Walker project was funded by the medical charity, Tenovus Tayside.

Duality of interest No author had any duality of interest in this study.

\section{References}

1. Chesley LC, Annitto JE, Cosgrove RA (2000) The remote prognosis of eclamptic women: sixth periodic report. Am J Obstet Gynecol 182:247

2. Fisher KA, Luger A, Spargo BH, Lindheimer MD (1981) Hypertension in pregnancy: clinical-pathological correlations and remote prognosis. Medicine 60:267-276 
3. Bryans CI (1966) The remote prognosis in toxaemia of pregnancy. Clin Obstet Gynecol 9:973-980

4. Sibai B, el-Nazer A, Conzalez-Ruiz A (1986) Severe pre-eclampsia in young primigravid women: subsequent pregnancy outcome and remote prognosis. Am J Obstet Gynecol 155:1011-1016

5. Laivuoria H, Tikkanen MJ, Ylikorkala O (1996) Hyperinsulinaemia 17 years after pre-eclamptic first pregnancy. J Clin Endocrinol Metab 81:2908-2911

6. He S, Silveira A, Hamsten A, Blomback K (1999) Haemostatic, endothelial and lipoprotein parameters and blood pressure levels in women with a history of pre-eclampsia. Thromb Haemost 81:538-542

7. Pouta A, Hartikainen AL, Sovio U et al (2004) Manifestations of metabolic syndrome after hypertensive pregnancy. Hypertension 43:825-831

8. Libby G, Smith A, McEwan NF et al (2004) The Walker Project: a longitudinal study of 48,000 children born 1952-1966 (aged 36-50 years in 2002) and their families. Paediatr Perinat Epidemiol 18:302-312

9. No authors listed (1999) Definition, diagnosis and classification of diabetes mellitus and its complications. Report of a WHO consultation. World Health Organization, Geneva

10. Morris AD, Boyle DI, MacAlpine R et al (1997) The diabetes audit and research in Tayside Scotland (DARTS) study: electronic record linkage to create a diabetes register. DARTS/MEMO Collaboration. BMJ 315:524-528

11. McLoone P (1991) Carstairs codes for Scottish postcode sectors from the 1991 census, Glasgow. Public Health Research Unit, University of Glasgow, Glasgow

12. Sattar N, Gaw A, Packard CJ, Greer IA (1996) Potential pathogenic roles of aberrant lipoprotein and fatty acid metabolism in pre-eclampsia. Br J Obstet Gynaecol 103:614-620

13. Kocyigit Y, Bayhann G, Atamer Y (2004) Serum levels of leptin, insulin-like growth factor-1 and insulin-like growth factor binding protein-3 in women with pre-eclampsia and their relationship to insulin resistance. Gynecol Endocrinol 18:341-348
14. Laivuori H, Lahermo P, Ollikainen V et al (2003) Susceptibility loci for pre-eclampsia on chromosomes 2p25 and 9p13 in Finnish families. Am J Hum Genet 72:168-177

15. Dahlquist GG, Patterson C, Soltesz G (1999) Perinatal risk factors for childhood type 1 diabetes in Europe. The EURODIAB Substudy 2 Study Group. Diabetes Care 22:1698-1702

16. Dahlquist GG (1997) Viruses and other perinatal exposures as initiating events for beta-cell destruction. Ann Med 29:413-417

17. Jonsdottir LS, Arngrimsson R, Geirsson RT, Sigvaldason H, Sigfusson N (1995) Death rates from ischaemic heart disease in women with a history of hypertension in pregnancy. Acta Obstet Gynecol Scand 74:772-776

18. Hannaford P, Ferry S, Hirsch S (1997) Cardiovascular sequelae of toxaemia of pregnancy. Heart 77:154-158

19. Smith GCS, Pell JP, Walsh D (2001) Pregnancy complications and maternal risk of ischaemic heart disease: a retrospective cohort study of 129290 births. Lancet 357:2002-2006

20. Barker DJP (1998) Mothers, babies and health in later life. Churchill Livingstone, Edinburgh

21. Ozanne SE, Hales CN (2002) Early programming of glucoseinsulin metabolism. Trends Endocrinol Metab 13:368-373

22. Bobrow C, Holmes R, Muttakrishna M, Murphy DJ, Soothill PW (2002) Maternal serum activin A, inhibin A and follistatin in pregnancies with appropriately grown and small for gestational age fetuses classified by umbilical artery Doppler. Am J Obstet Gynecol 186:283-287

23. Bobrow CS, Soothill PW (1999) Fetal growth velocity: a cautionary tale. Lancet $353: 1460$

24. Pell JP, Smith GCS, Dominiczak A et al (2003) Family history of premature death from ischaemic heart disease is associated with an increased risk of delivering a low birthweight baby. Heart 89:1249-1250

25. Brody SC, Harris R, Lohr K (2003) Screening for gestational diabetes; a summary of the evidence for the US Preventive Services Task Force. Obstet Gynecol 101:380-392 